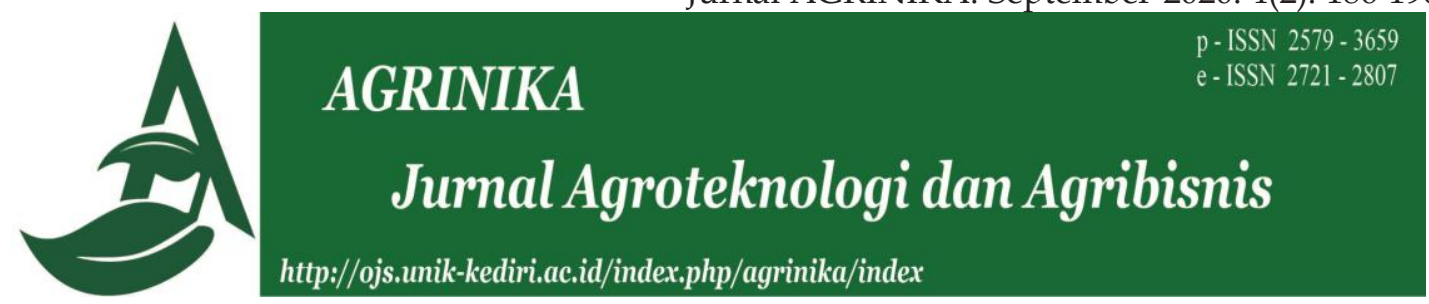

\title{
Aktivitas dan Tingkat Partisipasi Anggota dalam Usahatani Ternak Sapi Perah di Kelompok Tani Ternak Rejeki Lumintu Gunungpati, Kota Semarang
}

\author{
Agus Subhan Prasetyo ${ }^{1 *}$, Wulan Sumekar ${ }^{1}$, Dwiyana Anela Kurniasari ${ }^{2}$, Ali \\ Musabikin ${ }^{1}$ \\ ${ }^{1}$ Departemen Pertanian, Fakultas Peternakan dan Pertanian, Universitas Diponegoro, \\ Semarang, Indonesia \\ ${ }^{2}$ Program Studi Agribinis, Fakultas Pertanian,Universitas Wijaya Putra, Surabaya, Indonesia \\ *Korespondensi: setyo.subhan@live.undip.ac.id
}

Diterima 01 September 2020/Direvisi 14 September 2020/Disetujui 26 September 2020

\begin{abstract}
ABSTRAK
Kegiatan anggota dalam Kelompok Tani Ternak Rejeki Lumintu mengandung beberapa aktivitas berupa kegiatan usahatani dibidang sapi perah. Partisipasi merupakan tingkat kemauan individu dalam mengikuti kegiatan yang diselanggarakan oleh kelompok dalam upaya untuk mencapai tujuan kelompok. Penelitian ini bertujuan untuk mendeskripsikan dan menganlisis aktivitas dan tingkat partisipasi anggota dalam usahatani sapi perah di Kelompok Tani Ternak Rejeki Lumintu, Gunungpati, Kota Semarang. Penelitian ini menggunakan pendekatan analisis deskriptif dengan menggunakan skala likert. Hasil penelitian menunjukkan bahwa aktivitas usatani sapi perah mulai dari hulu sampai hilir. Sedangkan untuk tingkat partisipasi anggota dalam usahatani sapi perah memperoleh skor 12,61 dengan presentasi 84,09\% masuk kedalam kategori tinggi. Artinya anggota kelompok tani ternak Rejeki Lumintu telah berpartisipasi dengan baik dalam setiap kegiatan yang dilakukan oleh kelompok.
\end{abstract}

Kata kunci: Aktivitas; Kelompok tani; Partisipasi; Sapi perah; Usahatani

\begin{abstract}
One of many activities of members in Rejeki Lumintu's Cattle Farmers Group is farming of dairy cows. This study aimed to describe and analyze the activities and levels of members participation in Rejeki Lumintu's Cattle Farmers Group, Gunungpati, Semarang City. Participation is the level of an individual's willingness to participate in activities organized by the group in an effort to achieve group goals. This study employed a descriptive analysis approach using a Likert scale. The results showed that the dairy farming activities started from upstream to downstream. Meanwhile, the level of participation of members in dairy farming obtained a score of 12.61 with a presentation of $84.09 \%$ into the high category. This meant that members of Rejeki Lumintu's Cattle Farmers Group have participated well in every activity carried out by the group.
\end{abstract}

Keywords: Activities; Dairy cows; Farmer groups; Farming; Participation 


\section{PENDAHULUAN}

Sektor pertanian menjadi perhatian pemerintah baik dari tingkat pusat maupun tingkat daerah dengan fokus pembangunan sektor pertanian untuk meningkatkan kesejahteraan masyarakat. Pemerintah pusat melakukan pembangunan sektor pertanian dengan mengembangkan kelembagaan pertanian seperti pengembangan kelompok tani maupun gabungan kelompok tani. Pemerintah pusat melakukan pembangunan pertanian dengan mengeluarkan Peraturan Menteri Pertanian No. 62/PERMENTAN/SM.050/12/2016

Tentang Pembinaan Kelembagaan Petani dimana peraturan tersebut memuat mengenai pengembangan kelompok tani dengan fokus penguatan serta menciptakan kemandirian kelompok tani dan peningkatan kemampuan anggota dalam pengembangan usahatani. Hal ini menjadikan kelompok tani sebagai wadah pengembangan petani dan pembangunan pertanian dari skala lokal hingga regional.

Kelompok tani merupakan lembaga pertanian yang terbentuk karena memiliki kesamaan minat, kebutuhan, dan tujuan untuk meningkatkan dan mengembangkan usaha (Prasetyo et al., 2019). Kelompok tani menjadi kelembagaan pertanian penyalur program pemerintah dan berbagai kepentingan petani yang memiliki fungsi sebagai kelas belajar, wahana kerjasama, dan unit produksi (Anis et al., 2020; Rustandi \& Suhadji, 2017; Tolno et al., 2015). Kelompok tani ternak merupakan wadah kelembagaan pertanian untuk rakyat yang berprofesi sebagai peternak dan memiliki keinginan mengembangkannya. Anantanyu, (2011);
Amam et al., (2019), menyatakan bahwa kelembagaan petani yang afektif diharapkan mampu memotivasi petani untuk berpartisipasi dalam kelembagaan. Pengembangan kelompok tani ternak oleh pemerintah memerlukan kinerja kelompok tani yang baik dan peran pemerintah hingga ketingkat regional.

Kelompok tani ternak Rejeki Lumintu merupakan kelembagaan pertanian bagi peternak yang telah terbentuk sejak 1991 oleh masyarakat kelurahan Sumurrejo, Gunung-pati, Kota Semarang. Kelompok tani ternak Rejeki Lumintu menjadi kelompok yang dibina oleh Dinas Pertanian dan sering menjadi wadah penyaluran program oleh Dinas Pertanian Kota Semarang. Dinas Pertanian Kota Semarang sendiri memiliki program peningkatan produksi hasil peternakan dan pengembangan SDM pertanian sebagaimana direncanakan dalam Perubahan Kedua RENSTRA Dinas Pertanian Kota Semarang Tahun 2016-2021. Program tersebut diharapkan mampu membangun sektor peternakan, namun dalam pelaksanaannya memerlukan kelompok tani ternak yang baik sebagai wadah pelaksanaan program Dinas. Kelompok tani ternak harus didukung partisipasi anggota yang baik agar program yang diberikan ke kelompok dapat telaksana dengan baik (Muatip et al., 2019).

Partisipasi anggota merupakan kemauan anggota kelompok dalam memberikan ide, pemikiran, waktu, dan materi untuk kepentingan kelompok. Partisipasi anggota dalam memikirkan, melaksanakan, dan mengevaluasi kinerja kelompok memiliki peran dalam keberlangsungan dan keberhasilan kelompok. 
Sebuah program atau tujuan kelompok membutuhkan partisipasi anggota untuk saling bekerjasama dalam setiap kegiatan agar program dapat berjalan dengan baik dan tujuan tercapai. Melalui kerjasama dan partisipasi anggota yang terjadi membuat tujuan program dalam pembangunan pertanian dapat berhasil dan berjalan dengan baik (Puspitaningsih et al., 2016). Partisipasi anggota menjadikan anggota berkembang secara individu dan kelompok mampu berprestasi dan memiliki kecakapan kelompok yang baik.

Berdasarkan Keputusan Kepala Dinas Pertanian Kota Semarang No 520/7870 Tentang Penetapan Kelompok Tani dan Kelompok Wanita Tani Kota Semarang Tahun 2019, KTT Rejeki Lumintu ditetapkan sebagai kelompok tani kelas kemampuan Utama dimana hanya dua kelompok tani yang mencapai kelas utama se-Kota Semarang dari 384 kelompok tani. Kelompok tani ternak Rejeki Lumintu sering menjadi kelompok tani percontohan atas sebuah program Dinas Pertanian. Hal ini menunjukan kelompok memiliki kecakapan yang baik dan mempu menjadi rujukan bagi kelompok tani ternak lain terkait keorganisasisan maupun budidaya. Oleh karena itu penelitian ini bertujuan mendeskripsikan dan menganalisis aktivitas dan tingkat partisipasi anggota dalam usahatani sapi perah di Kelompok Tani Ternak Rejeki Lumintu.

\section{METODE}

Penelitian ini dilaksanakan di Kelompok Tani Ternak Rejeki Kelurahan Sumurejo, Kecamatan Gunungpati, Kota Semarang. Penelitian ini menggunakan metode deskriptif untuk mendeskripsikan dan menganlisis aktivitas dan tingkat partisipasi anggota dalam usahatani ternak sapi perah. Sugiyono (2009) menjelaskan bahwa penelitian deskriptif merupakan suatu studi untuk menemukan fakta dan dapat diinterpretasikan dengan tepat. Fakta atau fenomena tersebut dijelaskan dengan pemberian skor, menggunakan pengukuran dengan Skala Likert. Skala likert merupakan pengukuran variabel berdasarkan kategori respon berurutan (skala ordinal).

Responden dalam penelitian ini berjumlah 31 orang. Penentuan responden dilakukan secara purposive dengan pertimbangan bahwa mereka adalah anggota yang terlibat aktif dalam aktivitas usahatani sapi perah. Penilaian tingkat partisipasi anggota dalam usahatani sapi perah didasarkan pada lima indikator, yaitu 1) partisipasi dengan cara memberikan informasi, 2) partisipasi untuk insentif materil, 3) partisipasi pelaksanaan untuk memastikan berjalannya kegiatan usahatani berjalan baik, 4) pertisipasi Menyampaikan pendapat sebagai solusi persoalan, dan 5) partisipatif fungsional. Tingkat partisipasi anggota diukur dengan skor ordinal dalam tiga jawaban, masingmasing mewakili jawaban tinggi (3), sedang (2), dan rendah (1).

\section{HASIL DAN PEMBAHASAN}

Keadaan Kelompok Tani Ternak Rejeki Lumintu

Kelompok Tani Ternak Rejeki Lumintu merupakan kelompok tani tertua di Kecamatan Gunungpati yang berdiri sejak 1990. Kelompok terbentuk berdasarkan kemauan peternak di daerah 
Sumurejo untuk membentuk kelompok serta memperbaiki kondisi ekonominya. Sebanyak 15 peternak terdaftar dalam kelompok dan diketuai oleh Bapak Nahrowi pada saat pendiriannya. Nama kelompok Rejeki Lumintu dipilih berdasarkan tujuan pembentukan kelompok yang memiliki arti rejeki yang terus mengalir. Kegiatan beternak para anggota berawal dari pekarangan rumah masing-masing anggota. Berdasarkan aturan pemerintah terkait kesehatan lingkungan dan standar pembentukan kandang, aktivitas peternakan dipindahkan ke tanah pemerintah Kota Semarang di dukuh Kaum RT 02 RW 04 Kelurahan Sumurejo.

Kelompok menerima bantuan tanah dengan luasan 1,5 ha yang berupa ladang hijauan $8.000 \mathrm{~m}^{2}$ dan $7.000 \mathrm{~m}^{2}$ untuk bangunan kendang. Perkembangan kelompok yang dibarengi dengan perhatian pemerintah kota yang baik membuat kelompok terus mengembangkan fasilitas kelompok yang ada. Kelompok tani ternak Rejeki Lumintu kemudian membangun jalan untuk memudahkan distribusi pakan dan memudahkan konsumen susu untuk mengakses area peternakan. Kantor kesekretariatan kemudian dibangun untuk administrasi kelompok, menjamu tamu dan tempat penyelenggaraan program penyuluhan oleh Dinas Kota Semarang. Pembangunan dilanjutkan dengan pengadaan musholla dan toilet untuk keperluan ibadah anggota ataupun yangberkunjung di area kandang.

Kelompok tani ternak Rejeki Lumintu membangun rumah susu dan menerima bantuan alat penyimpanan susu untuk menjaga kualitas susu hasil produksi ketika pasar tidak mampu menyerap semua susu yang diproduksi. Produksi susu yang baik juga diiringi dengan efek limbah yang terus bertambah di area kandang komunal. Rumah kompos dibangun untuk mengolah limbah ternak menjadi pupuk kompos agar limbah ternak lebih bernilai dan tidak menjadi masalah lingkungan. Produksi kompos sebagian digunakan oleh kelompok yang mulai mencoba bertani padi organik dan sebagian lainya dijual ke kelompok tani lain.

Aktivitas Usahatani Sapi Perah di Kelompok Tani Ternak Rejeki Lumintu

Kegiatan anggota kelompok tani ternak Rejeki Lumintu dalam usahatani sapi perah terdiri dari kegiatan subsistem hulu, budidaya dan hilir. Anggota melakukan kegiatan di subsistem hulu berupa pemenuhan saprodi pakan, sarana pemeliharaan, dan pemerolehan bibit. Pakan yang digunakan peternak yaitu hijauan dan pakan pendamping terdiri dari tiga jenis bahan yaitu ampas tahu, bungkil ketela pohon dan konsentrat. Menurut Emawati, (2017) bahwa pakan yang diberikan kepada ternak harus sesuai dengan gizi yang diperlukan dan juga menjaga agar ternak memiliki daya makan yang baik. Anggota melakukan kegiatan pemenuhan pakan dengan membeli bahan pakan tambahan dan mencari hijauan dengan menanam sendiri hijauan pakan di ladang hijauan kelompok dan ladang yang dimiliki pribadi anggota. pakan hijauan yang ditanam ada tiga jenis hijauan yaitu rumput raja, rumput gajah odot dan rumput bede yang ditanam ketika akhir bulan penghujan dan akan dipanen dimusim kemarau. Sedangkan bibit yang digunakan yaitu 
berupa pedet, dara dan sapi laktasi yang diperoleh dari membeli dan dengan melakukan inseminasi buatan..

Proses pemberian pakan, sanitasi, perawatan dan pemerahan yang dilakukan rutin oleh peternak setiap harinya pada pagi dan sore hari. Anggota memberikan pakan dengan dua jenis pakan yaitu pemberian pakan penunjang produksi lalu pemberian pakan hijauan. Pakan penunjang diberikan ke ternak ketika telah melakukan sanitasi dan sebelum pakan hijauan. Pakan penunjang kebutuhan produksi diberikan $10-20 \mathrm{~kg}$ pakan per-ekor sesuai masa produksi sapi perah dengan komposisi $80 \%$ ampas tahu, $15 \%$ bungkil ketela dan $5 \%$ konsentrat, pemberian ampas tahu dan pakan tambahan dilakukan untuk menjaga konsistensi produksi susu. Hal ini didukung oleh Rusdiana \& Wahyuning, (2009) yang menyatakan bahwa peningkatan produksi dapat dilakukan dengan peningkatan pakan penunjang dengan memanfaatkan ampas tahu, ampas bir atau limbah singkong. Pemberian pakan hijauan tidak difokuskan untuk menunjang produksi namun hanya sebagai pemenuhan kebutuhan ternak untuk memakan hijauan. Pemberian hijauan 4-6 kg per-ekor sebagai pemenuhan kebutuhan sapi yang memakan rumput yang diberikan setelah pemberian pakan penunjang. Hasil penelitian Mukson et al., (2010) juga menyatakan bahwa pakan hijauan tidak berhubungan secara signifikan dengan produksi susu.

Anggota kelompok tani ternak Rejeki Lumintu melakukan kegiatan sanitasi setiap sebelum pemerahan. Hal ini dilakukan karena anggota menyadari bahwa sanitasi penting bagi menjaga kesehatan ternak dan kualitas susu yang baik. Kegiatan sanitasi yang dilakukan berupa membersihkan kandang dari feses, memandikan sapi dan tempat pakan menggunakan air bersih. kegiatan sanitasi dilakukan pada kandang, pakan dan lingkungan agar ternak terhindar dari penyakit. Utami et al., (2011); Wicaksono \& Sudarwanto, (2016), yang menyatakan bahwa kebersihan dalam sanitasi memiliki peran dalam kualitas susu yang dihasilkan dan kesehatan pada ternak. Ambing sapi, tubuh sapi, debu di udara, peralatan yang kotor dan manusia yang melakukan pemerahan adalah sumber kontaminasi potensial untuk produk susu sapi (Permatasari, 2018).

Setelah proses sanitasi selesai, anggota kelompok tani ternak Rejeki Lumintu melakukan kegiatan pemerahan. Pemerahan dilakukan dua kali dalam sehari yaitu pagi dan sore. Pemerahan dilakukan masih dengan cara manual dikarenakan produksi yang bersifat pribadi sehingga kuantitas memerah masih kecil dan mampu dikerjakan anggota. Anggota dalam memerah memperhatikan kebersihan puting dan kondisi ambing setiap sebelum memerah dan setelah pemerahan. Syarif dan Harianto (2011) menyatakan bahwa dalam manajemen pemerahan ternak perah perlu diperhatikan proses-prosesnya mulai dari proses pra-pemerahan meliputi pembersihan ternak dan kandang untuk menghindari terkontaminasi bakteri pada susu, proses pemerahan, dan pasca pemerahan yang meliputi penyaringan susu hingga pengolahan susu.

Anggota kelompok tani ternak Rejeki Lumintu memastikan terlebih 
dahulu kondisi puting ternak sebelum melakukan pemerahan. Putting sapi diolesi minyak agar memudahkan dalam proses pemerahan yang dilakukan. Pemerahan yang dilakukan peternak menggunakan teknik yang mereka kuasai berupa whole hand. Sebagaimana yang diungkapkan oleh Nugroho (2008) bahwa pada pemerahan susu ternak perah dengan pemerahan manual yang meliputi 3 cara manual dengan tangan yaitu whole hand, strippen, dan knivelen. Proses pemerahan dilakukan hingga susu diambing telah habis dan sebelum hormon pada puting habis agar tidak menyakitkan bagi ternak. Setiap kali pemerahan anggota mampu memperoleh 5-15 liter susu dari satu sapi yang diperah, kemudian susu yang dihasilkan akan dijual berupa susu murni. Susu yang dihasilkan mengalami proses penyaringan terelebih dahulu, kemudian dikemas perliter kedalam plastik. Susu yang sudah dikemas dijual dengan harga Rp 6.000 untuk pedagang, dan $\mathrm{Rp} 6.500$ untuk konsumen.

$\underline{\text { Tingkat Partisipasi Kelompok Tani Ternak }}$ $\underline{\text { Rejeki Lumintu }}$

Partisipasi anggota menjadi faktor keberhasilan aktivitas-aktivitas didalam kelompok tani. Aktivitas usahatani dan program kelompok tani dapat terlaksana dengan baik ketika adanya partisipasi anggota. Menurut (Susanto et al., 2017) partisipasi merupakan kegiatan keikutsertaan seseorang secara mental dan emosi dalam mengembangkan inisiatif dan kreativitasnya dalam mencapai tujuan kelompok dan mendukung kondisi kelompoknya. Sutanto \& Hendraningsih, (2011), juga menjelaskkan bahwa partisipasi diperlukan untuk menjamin keberlanjutan pembangunan, dimana individu dan lembaga harus saling berperan agar terjadi perubahan dalam konteks pembangunan.

Tingkat pasrtisipasi anggota dapat dilihat dari partisipasi dengan cara memberikan informasi, partisipasi untuk insentif materil, partisipasi pelaksanaan untuk memastikan berjalannya kegiatan usahatani berjalan baik, pertisipasi menyampaikan pendapat sebagai solusi persoalan, dan partisipatif fungsional. Hasil penelitian menujukkan bahwa tingkat partisispasi anggota Kelompok Tani Ternak Rejeki Lumintu dalam usahatani sapi perah berada pada katagori tinggi dengan rerata total 12,61 atau 84,09\% dari total skor maksimal 18 . Pengukuran indikator disajikan pada Tabel 1.

\section{Partisipasi dengan cara memberikan informasi}

Skor partisipasi dengan cara memberikan informasi pada penelitian ini adalah 2,61 dengan persentase $87,10 \%$ termasuk dalam kategori tinggi. Kondisi ini disebabkan oleh aktifnya anggota dalam memberikan informasi kepada sesama anggota terutamnya dalam kegiatan rutin kelompok. Falo \& Nubatonis, (2017) menyatakan bahwa pertemuan rutin menjadi media bagi anggota untuk bertukar informasi terkait dengan informasi terbaru khususnya usahatani sapi perah. Kondisi ini terlihat dimana diwaktu pertemua rutin terdapat anggota yang memiliki pengetahuan lebih mengenai berternak dan berorganisasi memberikan informasi ke anggota lain mengenai jadwal kehamilan dan cara perawatan ternak hamil kepada kelompok. 
Agus Subhan Prasetyo, Aktivitas dan Tindakan...

Tabel 1. Rekapitulasi tingkat partisipasi anggota dalam usahatani sapi perah di kelompok tani ternak lumintu

\begin{tabular}{llrrr}
\hline No & \multicolumn{1}{c}{$\begin{array}{c}\text { Tingkat Partisipasi Anggota } \\
\text { Kelompok Tani Tenak Rejeki } \\
\text { Lumintu }\end{array}$} & $\begin{array}{c}\text { Skor rata-rata } \\
\text { Maks }\end{array}$ & $\begin{array}{c}\text { Skor } \\
\text { Rata-rata }\end{array}$ & $\begin{array}{c}\text { Persentase } \\
\%\end{array}$ \\
\hline 1 & $\begin{array}{l}\text { Partisipasi dengan cara } \\
\text { memberikan informasi }\end{array}$ & 3 & 2,61 & 87,10 \\
2 & $\begin{array}{l}\text { Partisipasi untuk insentif materil } \\
3\end{array}$ & 3 & 2,13 & 70,97 \\
$\quad \begin{array}{l}\text { Partisipasi pelaksanaan untuk } \\
\text { memastikan berjalannya kegiatan } \\
\text { usahatani berjalan baik }\end{array}$ & 3 & 2,48 & 82,80 \\
4 & $\begin{array}{l}\text { Pertisipasi Menyampaikan } \\
\text { pendapat sebagai solusi persoalan }\end{array}$ & 3 & 2,58 & 86,02 \\
5 & Partisipatif fungsional & 3 & 2,81 & 93,55 \\
\hline & \multicolumn{1}{c}{ Total } & 15 & 12,61 & 84,09 \\
\hline
\end{tabular}

Sumber: Data primer diolah

Partisipasi untuk insentif materil

Menurut Uceng et al., (2019) partisipasi untuk insentif materiil yaitu anggota kelompok berpartisipasi dengan cara menyediakan sumber daya seperti tenaga kerja, demi mendapatkan makanan, upah, ganti rugi, dan sebagainya. Nilai partisipasi untuk insentif materil dalam penelitian ini adalah 2,13 dengan persentase $70,97 \%$ termasuk dalam kategori sedang. Kategori sedang dikarenakan masih adanya anggota yag tidak melakukan pembayaran jika tidak menghadiri pertemuan rutin tanpa alasan yang sesuai dengan kesepatan yang telah di setujui bersama. Terdapat anggota memberikan alasan tidak mengetahui keputusan tersebut senhingga mereka keberatan untuk membayarkan denda yang telah disepakati.

\begin{tabular}{llr} 
Partisipasi & pelaksanaan & untuk \\
\hline memastikan berjalannya & kegiatan \\
\hline usahatani berjalan baik &
\end{tabular}

Tingkat partisipasi pelaksanaan untuk memastikan berjalannya kegiatan usahatani berjalan baik menunjukan katagori tinggi dengan skor 2,48 dengan presentase $82,80 \%$. Hal ini terlihat dari anggota Kelompok Tani Ternak Rejeki Lumintu terlibat secara langsung dalam proses perencanaan, pelaksanaan dan evaluasi dari sebuah kegiatan. Peternak terlibat dalam pembahasan dan perencanaan pendistribusian bantuan Dinas kemudian mengikuti dan mengawasi pelaksanaan pada kelompok dan mengevaluasi kegiatan tersebut untuk pembahasan program selanjutnya. Peternak terlibat secara langsung dalam proses penanganan permasalahan kemitraan pakan dari perencanaan sampai evaluasi kemitraan yang telah dilaksanakan. Hal ini sesuai dengan 
pendapat dari Anis et al., (2020) yang menyatakan bahwa partisipasi anggota yang baik memiliki anggota yang terlibat langsung dalam proses perencanaan, pelaksanaan dan evaluasi kegiatan.

\section{Pertisipasi menyampaikan pendapat sebagai solusi persoalan}

Skor partisipasi menyampaikan pendapat sebagai solusi persolan termasuk dalam kategori tingga denga nilai 2,58 dengan persentase 86,02\%. Anggota kelompok tani ternak Rejeki Lumintu memiliki respon yang baik dan ikut bereaksi pada permasalahan yang dihadapi oleh kelompok. Sebagaimana yang di katkan oleh Maleba \& Rori, (2015) bahwa keikutsertaan dalam berespon spontan terhadap masalah atau kepentingan merupakan bentuk partisipasi anggota kelompok dalam upaya mencapai tujuan kelompok.

Hal ini terlihat dari anggota kelompok tani ternak Rejeki Lumintu ikut berpartisipasi dengan memberikan pendapat pada pembahasan masalah mengenai permasalahan pakan ternak, pendistribusian bantuan Dinas dan persiapan lomba kelompok pada pertemuan rutin yang diselenggarakan. Selain itu, anggota kelompok tani ternak Rejeki Lumintu memiliki rasa bertanggungjawab yang baik. Anggota kelompok tani ikut merasa tanggungjawab atas program dan kegiatan yang ada dikelompok.anggota turut memikirkan jalan keluar yang dihadapi oleh kelompok.

\section{Partisipatif Fungsional}

Partisipasi fungsional merupakan partisipasi dari anggota kelompok dengan membentuk kelompok untuk mencapai tujuan bersama (Uceng et al., 2019).
Penelitian ini menunjukkan partisipasi fungsional termasuk dalam kategori tinggi dengan skor 2,81 atau presentase 93,55 $\%$. Kondisi ini terlihat dari ketelibatannya anggota kelompok tani ternak Rejeki Lumintu dalam menentukan tujuan kelompok. Anggota kelompok juga turut andil dalam kegiatan kelompok tani ternak untuk guna mencapai tujuan kelompok seperti beternak dengan efektif, menaikan kesejahteraan dan berprestasi. Ramadoan et al., (2013) yang menyatakan bahwa dengan adanya tujuan yang ingin dicapai dalam sebuah kelompok akan menambah semangat dan menjadi motivasi bagi anggota untuk berpartisipasi.

Kondisi lain, tingginya partisipasi fungsional terlihat dari tingginya tingkat kehadiran anggota anggota kelompok tani ternak Rejeki Lumintu dalam pertemuan rutin. Pertemuan rutin yang ada dilakukan satu kali setiap bulannya. Anggota selalu mengusahakan untuk menghadiri pertemuan yang diselenggarakan oleh kelompok dan akan menyampaikan ijin jika berhalangan melaui anggota lainya. Selain itu, anggota anggota kelompok tani ternak Rejeki Lumintu selalu hadir dalam kegiatan penyuluhan yang diseleenggarakan oleh Dinas Pertanian.

\section{KESIMPULAN}

Berdasarkan hasil dan pembahasan maka dapat disimpulkan bahwa aktivitas anggota kelompok tani ternak Rejeki Lumintu dalam usahatani sapi perah dimulai dari pemenuhan kebutuhan sarana produksi, dan kegiatan budidaya seperti pemberian pakan, sanitasi, sanitasi dan perawatan, sampai pemerasan susu sapi hingga penjualan. 
Sedangkan indikator tingkat partisispasi anggota dalam usaha tani ternak di Kelmpok Tani Ternak Rejeki Lumintu termasuk dalam kategori tinggi dengan skor 12,61 datau $84,09 \%$ dari total skor maksimal 15. Skor tersebut menunjukkan bahwa anggota dapat mendukung tercapai tujuan dari sebuah kelompok.

\section{DAFTAR PUSTAKA}

Amam, A., Jadmiko, M. W., Harsita, P. A., \& Poerwoko, M. S. (2019). Model Pengembangan Usaha Ternak Sapi Perah Berdasarkan Faktor Aksesibilitas Sumber Daya. Jurnal Sain Peternakan Indonesia, 14(1), 61-69.

https://doi.org/10.31186/jspi.id.14.1.6 1-69

Anantanyu, S. (2011). Kelembagaan Petani: Peran Dan Strategi Pengembangan Kapasitasnya. SEPA, 7(2), 102-109.

Anis, S. M., Effendy, L., \& Muslihat, E. J. (2020). Partisipasi Anggota Kelompoktani Dalam Penyusunan Rencana Definitif Kelompok/Rencana Definitif Kebutuhan Kelompok. Jurnal Penyuluhan Pertanian, 9(1), 37-42.

Emawati, S. (2017). Profitabilitas Usahatani Sapi Perah Rakyat di Kabupaten Sleman. Sains Peternakan, 9(2), 100. https://doi.org/10.20961/sainspet.v9i 2.4820

Falo, M., \& Nubatonis, A. (2017). Partisipasi Anggota Kelompok Tani dalam Berusahatani Bawang Putih di
Desa Sallu Kecamatan Miomaffo Barat Kabupaten Timor Tengah Utara. Agrimor, 2(02), 17-22. https://doi.org/10.32938/ag.v2i02.268

Maleba, E., \& Rori, Y. P. I. (2015). This study aims to determine the participation of members in the development of farmer groups in the village Soatobaru Galela District West . The research is expected to provide information regarding participation of farmer group members on farmer group d. $A S E$, 11(2A), 47-60.

Muatip, K., Purwaningsih, H., Setianto, N. A., Sugiarto, M., Widiyanti, R., Safitri, L., \& Istiqomah, W. (2019). Organizational Commitment of Members of the Dairy Farmer Group in Banyumas Regency. IOP Conference Series: Earth and Environmental Science, 372(2019). https://doi.org/10.1088/17551315/372/1/012004

Mukson, M., Ekowati, T., Handayani, M., \& Gayatri, S. (2010). The potency of dairy cattle agribusiness development in Semarang Regency, Central Java. Journal of the Indonesian Tropical Animal Agriculture, 35(3), 179-184. https://doi.org/10.14710/jitaa.35.3.17 9-184

Permatasari, R. I. (2018). Higiene, Sanitasi dan Kualitas Bakteriologis Susu Sapi di Dusun Krajan, Desa Gendro, Kecamatan Tutur, Kabupaten Pasuruan. Jurnal Kesehatan Lingkungan, 10(4), 343- 
350.

Prasetyo, A., Safitri, R., \& Hidayat, K. (2019). Strategi Komunikasi Ketua Dalam Meningkatkan Eksistensi Kelompok (Kasus di Kelompok Tani Sidodadi di Desa Junrejo, Kecamatan Junrejo Kota Batu Jawa Timur). Habitat, 30(1), 26-34. https://doi.org/10.21776/ub.habitat.20 19.030.1.4

Puspitaningsih, O. S., Utami, B. W., \& Wijianto, A. (2016). Partisipasi Kelompok Tani dalam Mendukung Program ... Puspitaningsih et al. Caraka Tani, 31(2), 79-85.

Ramadoan, S., Muljono, P., \& Pulungan, I. (2013). Peran Pksm Dalam Meningkatkan Fungsi Kelompok Tani Dan Partisipasi Masyarakat Di Kabupaten Bima, Ntb. Jurnal Penelitian Sosial Dan Ekonomi Kehutanan, 10(3), 199-210. https://doi.org/10.20886/jsek.2013.10 .3.199-210

Rusdiana, S., \& Wahyuning, K. (2009). UPAYA PENGEMBANGAN AGRIBISNIS SAPI PERAH DAN PENINGKATAN PRODUKSI SUSU MELALUI PEMBERDAYAAN KOPERASI SUSU. Forum Penelitian Agro Ekonomi, 27(1), 43-51.

Rustandi, Y., \& Suhadji, R. (2017). Keragaan Evaluasi Fungsi Kelembagaan Kelompok Tani di Kecamatan Papar Kabupaten Kediri Jawa Timur The Evaluation Overview Institutional Functionof The Kelompoktani In kecamatan Papar
Kabupaten Kediri East Java. Agrica Ekstensia, 11(2), 55-60.

Susanto, D. A., Widodo, S., Sudrajat, R., \& Saputra, H. J. (2017). PENDAMPINGAN KAMPUNG TEMATIK MLATIHARJO GUMBREGAH SEMARANG TIMUR KOTA SEMARANG Universtas PGRI Semarang. SEMINAR NASIONAL HASIL PENGABDIAN KEPADA MASYARAKAT (SNHPKM)-VII, 567573.

Sutanto, A., \& Hendraningsih, L. (2011). Analisis keberlanjutan usaha sapi perah di kecamatan ngantang kabupaten malang. Jurnal Gamma, $7(1), 1-12$.

Tolno, E., Kobayashi, H., Ichizen, M., Esham, M., \& Balde, B. S. (2015). Economic Analysis of the Role of Farmer Organizations in Enhancing Smallholder Potato Farmers' Income in Middle Guinea. Journal of Agricultural Science, 7(3). https://doi.org/10.5539/jas.v7n3p123

Uceng, A., Ali, A., Mustanir, A., \& Nirmawati. (2019). Analisis Tingkat Partisipasi Masyarakat Terhadap Pembangunan Sumber Daya Manusia Di Desa Cemba Kecamatan Enrekang Kabupaten Enrekang. Jurnal Moderat, 5(2), 1-17. https://jurnal.unigal.ac.id/index.php/m oderat/article/view/2125

Utami, K. B., Radiati, L. E., Surjowardojo, P., Peternakan, F., \& Brawijaya, U. (2011). Kajian kualitas susu sapi 
Agus Subhan Prasetyo, Aktivitas dan Tindakan...

perah PFH ( studi kasus pada anggota Kope- rasi Agro Niaga di

Kecamatan Jabung Kabupaten Malang ). 24(2), 58-66.

Wicaksono, A., \& Sudarwanto, M. (2016). Peningkatan Kualitas Susu Peternakan Rakyat di Boyolali melalui Program Penyuluhan dan Pendampingan Peternak Sapi Perah. Agrokreatif Jurnal IImiah Pengabdian Kepada Masyarakat, 2(2), 55-60. https://doi.org/10.29244/agrokreatif.2 .2.55-60 